\title{
Vertical Articulation and Content Relevance of the Senior High School Economics Curriculum: Case of Ghana
}

\section{Bernard Yaw Sekyi Acquah ${ }^{1}$ Anthony Akwesi Owusu ${ }^{2 \rtimes}$}

${ }^{2}$ Department of Business and Social Sciences Education, University of Cape Coast, Ghana. Email:bacquah@ucc.edu.gh Tel: +233(0)242288715

'Email: anthony.orousu@ucc.edu.gh Tel: +233(0)209665424

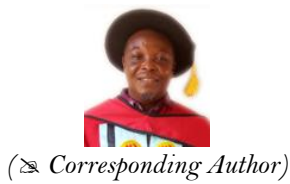

( Corresponding Author

\begin{abstract}
The school curriculum is often the formal document designed for teachers to treat topics that allow for the impartation of knowledge and the development of competencies that prepare students for further studies. Achieving this depends mainly on its content structure and sequencing. The aim of this study is two-fold: to find the extent of vertical articulation of topics in the economics syllabus that makes it possible for the syllabus to achieve its purpose of preparing students for further studies; and to explore the extent to which the syllabus is up-to-date and relevant in dealing with current economic issues. Document analysis was used to analyse the syllabus, while eight (8) service teachers purposively selected were interviewed. The study found that the SHS economics curriculum lacked vertical content articulation regarding the learning competencies for Forms 1 to 3. Also, the interviews revealed that the curriculum is not up-to-date though relevant since many evolving economic concepts have not been captured. The study supports the call for curriculum change and alignment of content to improve its vertical articulation and coherence and its currency and relevance in helping to equip students with the requisite knowledge and fundamental economic tools for their daily survival.
\end{abstract}

Keywords: Syllabus, Economics curriculum, Vertical articulation, Content relevance, Senior High School.

Citation | Bernard Yaw Sekyi Acquah; Anthony Akwesi Owusu (2021). Vertical Articulation and Content Relevance of the Senior High School Economics Curriculum: Case of Ghana. Asian Journal of Education and Training, 7(3): 169-178.

History:

Received: 24 May 2021

Revised: 18 June 2021

Revised: 18 June 2021

Published: 4 August 2021

Licensed: This work is licensed under a Creative Commons Attribution 3.0 License (cc)

Publisher: Asian Online Journal Publishing Group
Acknowledgement: Both authors contributed to the conception and design of the study.

Funding: This study received no specific financial support.

Competing Interests: The authors declare that they have no conflict of interests.

Transparency: The authors confirm that the manuscript is an honest, accurate, and transparent account of the study was reported; that no vital features of the study have been omitted; and that any discrepancies from the features of the study have been omit
study as planned have been explained.

Ethical: This study follows all ethical practices during writing.

\section{Contents}

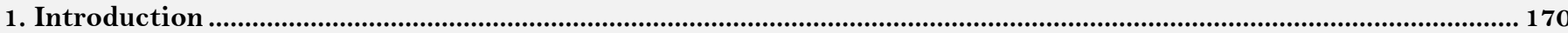

2. Method

3. Results

172

4. Discussions

5. Conclusion

177

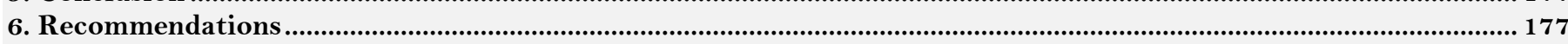

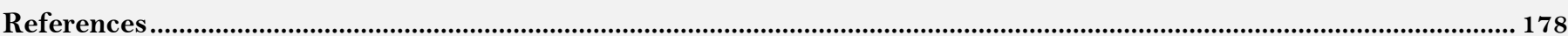




\section{Contribution of this paper to the literature}

This paper contributes by filling the gap in the literature on the extent to which the economics curriculum for Ghana provides students the necessary skills for further study of economics and also how well the content is up-to-date in responding to economic issues in the country. Specifically, the study provides scientific evidence on the extent to which the content of the SHS economics curriculum is vertically articulated and the extent of its relevance to the socioeconomic realities of Ghanaian life. The paper's finding provides the impetus for curricula review debates that can lead to the formulation of policy to keep the curriculum germane and in congruence with global economic changes.

\section{Introduction}

Articulation, either vertical or horizontal, refers to the interconnectedness of concepts within a curriculum (Kannan, 2016). There is vertical articulation when the lessons to be taken in a subject are related to those occurring later in the curriculum sequence, implying the organisation of content according to the sequence and continuity of learning within a given subject domain. A balance between the vertical and horizontal articulation of the curriculum helps the learners gain knowledge and utilise it to achieve their goals (Kannan, 2016). The content standards of the curriculum continue to change tremendously to meet the principal demands of globalisation defies and meeting the needs of modern technological-based society (Morales, 2017). However, any exercise that prioritises the redesign of curricula content without recourse to students' needs and interests could harm their future learning aspirations.

The school curriculum is usually designed around topics that allow for developing competencies as students master the principles and standards in increasing complexity (De-Juanas Oliva, Martín del Pozo, \& Pesquero Franco, 2016). The present study focuses on how the topics and learning competencies in the SHS economics syllabus are sequentially arranged across three forms in a progressive spiral manner. Gibbs (2014) explained that the spiral curriculum designs seen in most schools' curricula, despite covering many topics, do not enhance the acquisition of basic economic concepts that promote understanding of higher-level concepts. Experience has shown that students often lose ground in grasping concepts central to further studies in a particular discipline.

Economics is a necessary subject of study because it explains the allocation of scarce resources among alternative and competing ends to satisfy human wants (Allocation of Scarce Resources, 2013). Spash (2002) also states that economics is worthy of study because it makes it easier to institute practical measures to promote welfare. Some scholars in economics see it as a social subject, while others have aligned it to the pure sciences.

In Ghana, students get to study economics when they get to senior high school. Even at this level, not all students choose to study the subject. The reason is that, as an elective subject, only students offering the General Arts programme and Home Economics (depending on the subject combination), and students offering Business programmes have the chance to study economics. Students who pursue General Arts and Business programmes with elective subject combinations such as Geography, Government, Elective Mathematics (E-Maths) among other subject disciplines. Generally, all students who pursue programmes in Business also study economics. The rationale for teaching economics in senior high schools in Ghana is to ensure that the subject "helps to provide an effective framework for individuals, firms and governments to identify their basic economic problems, and make necessary decisions and policies for raising the living standards of people and societies" (Teaching Syllabus for Economics, 2010). The study of economics aids the individual to develop skills for managing his/her economic resources efficiently both in the family and in business. (Shahrokh, 1998).

Vertical articulation of the curriculum refers to the set competencies taught to students in one lesson, course, or grade level that prepares them for the next level of study with higher competencies. A vertically articulate curriculum is one in which learning in one lesson, topic or subject, or grade level prepares students for the next lesson, topic or subject, or form/class. In vertical articulation, teaching is purposefully structured and logically sequenced so that students are learning the knowledge and skills that will progressively prepare them for more challenging, higher-level tasks. Curriculum mapping helps to ascertain the extent to which contents are logically sequenced across class/form levels such that students' previous learning is built on by subsequent learning in a progressive manner, thereby preparing students for more challenging, higher-level academic tasks (Curriculum Mapping, 2018).

Lack of vertical articulation of the curriculum could hamper the curriculum's aim of further equipping students with the necessary economic skills to pursue further economics studies. There is, therefore, a need to find out the vertical articulation of the curriculum. Questions for exploration include, by what degree are topics which are introduced from the early year (Form 1) reinforced in year two (Form 2), and reinforced in the final year (Form 3) till the concepts are mastered. Figure 1 illustrates a conceptual theorisation of the study. It predicts that all other things being equal when topics from the initial schooling years of students are reinforced in the ensuing school years, economic concepts are properly mastered, paving the way for acquiring the essential skills for studying economics at the tertiary level. In this case, the curriculum may be described as having the spiral property and, therefore, fit-for-purpose, not meriting a review. In contrast, if the topics do not find reinforcement in the subsequent years, then the curriculum lacks the spiral property, which implies that concepts are not reinforced and mastered, making it impractical to equipping students with the skills for further development study of economics. 
Year 1

Year 2

Year 3

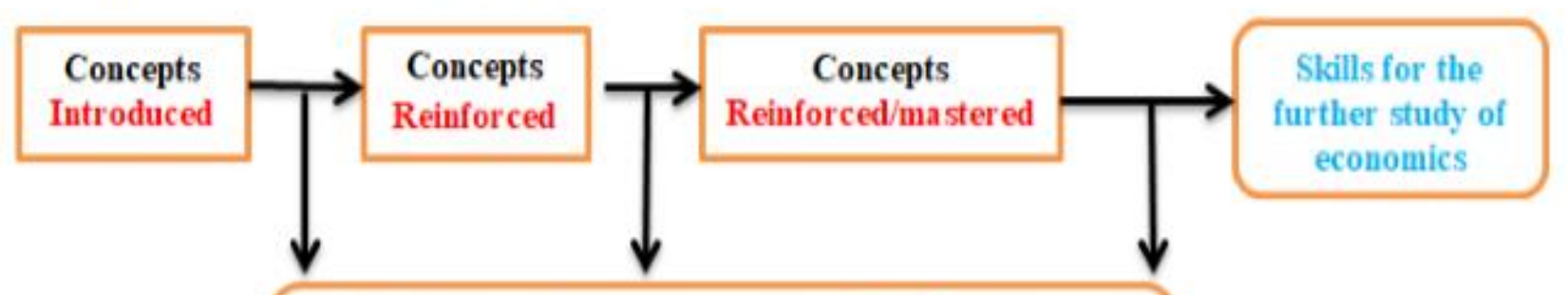

A Good Spiral Curriculum Needing no/Little Review as far as aim of equipping students with sialls for further study of economics is concerned.

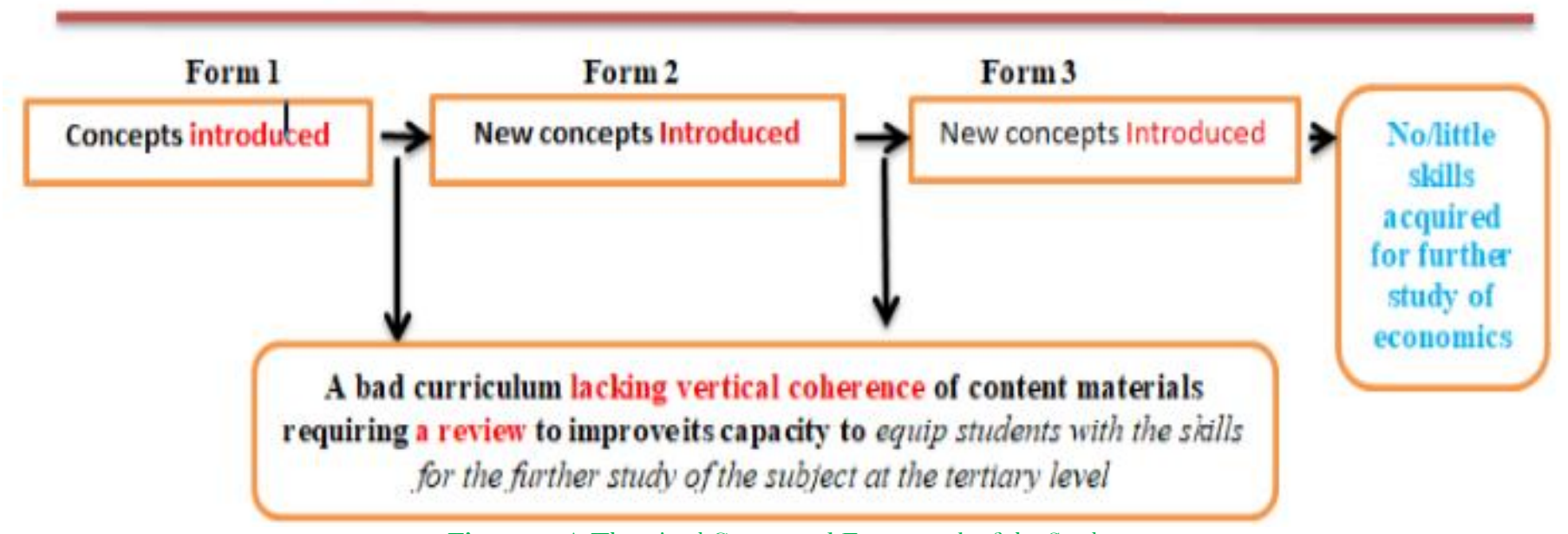

Figure-1. A Theorized Conceptual Framework of the Study.

\subsection{Problem}

Economics education has clear goals to produce economically empowered citizens with critical thinking and problem-solving skills to help deal with the many economic challenges of Ghana. The syllabus makes it explicit that high school economics is intended to "further equip students with the basic tools required for further studies in the subject" (Teaching Syllabus for Economics, 2010). As long as Ghana remains a sovereign state, she needs her citizens to be economically literate. The problem is that the number of students willing to enrol for further studies in economics at the tertiary level continues to decrease (Marangos, Fourmouzi, \& Koukouritakis, 2013). This worrying phenomenon has been blamed on students' weak foundation in the subject at the SHS level. One way to equip students with skills to study economics further is to ensure that the subject's content possesses vertical articulation allowing for mastery of concepts. The curriculum's ability to equip students to study economics at the tertiary level further is key to the quest for the socio-economic development of the country. Again, the curriculum needs to be "up-to-date and relevant" in tackling the numerous evolving economic issues (Paraskeva, 2020). In this regard, we posed two vital questions: To what extent does the content of the SHS economics curriculum possess vertical articulation, thus being able to prepare students for further studies in economics? Can the SHS economics curriculum be said to be up-to-date and relevant in tackling the numerous evolving economic challenges confronting Ghana? These important issues have been largely unexplored in Ghana and Africa as a whole, hence our motivation to conduct this study.

\subsection{Theoretical Underpinning}

The spiral curriculum of the cognitive theory Jerome Bruner developed was strengthened by Gibbs (2014) study. The spiral curriculum, which entails the regular re-visiting of educational topics throughout a student's education, was the approach we used. As long as curricula content is re-visited, the student gains a profound understanding of concepts, the benefit of which is the reinforcement of information leading to mastery of knowledge. Through spiralling, topics in the curriculum are taught over and over. Re-engaging already taught materials repeatedly consolidates learning based on prior knowledge and helps students build knowledge over time. Bruner explained that young learners could comprehend the most complex material if those materials are properly structured and presented spirally. He explained that the spiral curriculum is based on certain principles that include re-visiting topics, themes many times, making learning cyclical; increasing the complexity of topics or themes with each re-visit, increasing learning in-depth; and making a new relationship with old learning. This makes prior knowledge critical in learning. The importance of the careful arrangement of topics and competencies in a spiral manner has been documented in the literature (Brooks, 2010; Kilic, 2014). Each time information is introduced and re-visited, the material learnt is reinforced and solidified (Kridel, 2010; Masters \& Gibbs, 2007). Although there is no clear research evidence of the overall effects of the spiral curriculum on student learning, it has been touted as improving student learning outcomes (Herrick, Jacob, \& Richardson, 2003). Despite its advantages, the spiral curriculum has also been heavily criticised for being time-consuming.

\section{Method}

Investigators used the qualitative design approach, which is aligned with the case study tradition. The design was made evaluative to allow for the appraisal of the vertical articulation of the SHS economic curriculum content. The current research design helped investigators conduct the study on evaluating the implementation of the SHS economics curriculum in Ghana. The reason for the choice of this design was a concern by the investigators to obtain answers to whether, per the vertical structure of the content of the syllabus, it is able to 
build skills and competencies in students for them to pursue further studies in economics to the higher level, notwithstanding the criticism that this research design is subjective. The study explored the SHS economics curriculum relative to its content and sequence of learning competencies adjusted to the spiral progression approach of increasing complexity across various forms from Form 1 to Form 3. To do this, we used document analysis via curriculum mapping of the syllabus to ascertain whether there was a discrepancy or gap in the standards and competencies, which hampers the successful enactment of the intended curriculum by teachers (Li \& Harfitt, 2016).

Document analysis is a systematic procedure for revising or assessing printed or electronic documents. Like any analytical method in qualitative research, it entails examining and interpreting data to get an in-depth understanding of a phenomenon (Bowen, 2009). In this study, investigators examined the economics syllabus, which contains text (words) and images recorded in the written curriculum. The purpose for choosing to use this method was to enable investigators to triangulate or combine this method with other qualitative methods to study the phenomenon of vertical articulation that leads to coherence (Bowen, 2009). We drew upon this method through curriculum mapping and an interview session (Conducting Research Interviews, 2015) to seek convergence and corroboration through these different data sources. The triangulation of data helped the researchers to provide 'a union of evidence that warrants credibility'. The investigators corroborated the findings across data sets through the methodological triangulation, thereby reducing the suspicion of possible biases existent in single studies (Bowen, 2009).

This curriculum analysis approach was also used to determine the consistency and alignment of competencies along with the content areas across all forms. Through document analysis, investigators were able to identify the flaws and the misalignments of the competencies of the SHS economics curriculum in addition to the overall coherence of a course of study (Key Competence Standards of Local College Students, 2020). The present study focused on the vertical articulation of the content of the SHS economics curriculum across all forms from Form 1 to Form 3.

Also, we interviewed eight (8) purposively selected in-service SHS economics teachers (4 Males, 2 Females). The selection was based on teaching experience (those who had taught for more than five years) in the teaching service and resident in Cape Coast, Central Region. To ensure confidentially, we assigned them pseudonyms (Int 1, Int2, Int3, Int4, Int5, Int6, Int7, Int8). Through informed formal consent, we sought their permissions to partake in the study voluntarily.

\section{Results}

\section{Document Analysis of the syllabus}

\section{Research Question 1: To what extent does content of the SHS economics curriculum possess vertical articulation?}

Document analysis through concept mapping and interviews helped investigators to answer this research question. The syllabus was the main document that was analysed. First, the research question(s) were formulated and the syllabus was obtained and the necessary contents were sampled. The contents were transposed into tables, preparing them for analysis. We then developed a codebook based on which the contents were unitised and coded. We described the content and compared the contents between the documents under analysis. Finally, we reported and summarised the qualitative findings with the use of quotations, paraphrases or other references in the text (syllabus extract). The learning competencies in each of the content areas, namely, the Price Theory (Demand) was introduced in Forms 1. 2, and 3.

There are key stage standards of economics, as shown in Table 1, which are based on year 1, year 2, and year 3 (SHS 1, SHS 2, and SHS 3). The Key Stage Standards emphasise both the content and performance standards requirements that the student needs to perform with the aid of the appropriate instructional resources that promote the acquisition of 21 st-century skills. They also guide the economic knowledge, skills, and values that the students should demonstrate at the end of the year.

To "describe" something after it has been taught implies student acquisition of "knowledge". To explain, summarise, give examples, etc., implies student understanding of the material taught. But to describe the behaviour using "understand" shows that the performance behaviour is not behavioural and measurable. One cannot measure the extent to which the student understands. Likewise, developing, planning, constructing, etc., implies the ability of students to create, innovate, or synthesise knowledge. As seen, every one of the specific objectives in the syllabus holds an "action verb" which describes the behaviour that the student should demonstrate following an instruction. Analysis of the content also shows that in the first year, it is anticipated that students go through 'the fundamental concepts in economics, 'factors of production, economic systems (economies), 'price theory' (demand), and 'price theory' (supply). In the second year, students study 'the theory of production', 'prices of factors of production, 'the theory of costs and revenue', 'distributive trade', 'the theory of consumer behaviour', 'the national income accounting and determination', and 'agriculture and industry'. In the third year, 'money and financial institutions', 'public finance', 'international trade', 'economic co-operation', 'economic development planning', and 'contemporary economic issues'. Like all the years, there are a set of learning competencies associated with 21 performance standards that students are taught and expected to perform at the end of the first year. In the second year, the learning competencies are associated with 31 performance standards, while there are 25 performance outcomes that students are expected to perform at the end of each academic year. The use of "understand" as a performance indicator appears eleven (11) times in the first year, 16 times in the second year, and 12 times in the third year.

One distinctive feature of the current economics curriculum is the latent continuity and sequencing of economic concepts or themes. The themes appear to be logically sequenced to understand concepts. Table 2 highlights the detailed distribution of the learning competencies for the three-year SHS economics curriculum for the three forms. The learning competencies are organised and sequentially arranged. Still, these are not spiral in nature to allow for progression where students build on the previously learnt concepts to perform the required skills and values based on form-level standards. 
Table-1. Key Stage Standards of the SHS Economics Curriculum

Stage Key Stage Standards

Fundamental Concepts in Economics: At the end of this lesson, the student is expected to:

SHS 1 1. understand the basic principles of the management of scarce resources 2. understand the meaning of economics 3. appreciate the scope of economic activity 4. recognise the classification and contributions of various economic activities 5. appreciate the use of statistical tools in economic analysis.

Factors of Production (Kinds of Resources Or Inputs) General objectives: The student will: 1. understand the types of factors of production and their meanings. 2. appreciate the importance of the availability of various factors of production 3. be aware of various population and labour issues. 4. recognise and understand the various business units and their advantages and disadvantages.

Economic Systems (Economies) General objectives: The student will: 1. understand various economic systems and how they perform their functions 2 . be aware of the different types of unemployment, their causes and remedies.

Price Theory (Demand) General Objectives: The student will: 1. understand the importance of prices in decision making by consumers and producers 2 . be aware of the meaning of demand and the factors determining demand. 3. understand and identify the various types of elasticity of demand and their importance.

Price Theory (Supply) General Objectives: The student will: 1. understand the meaning of supply and the factors determining it. 2. appreciate the concept of elasticity of supply, its measurement, the factors affecting it and its importance. 3. understand the concept of equilibrium price and how it is determined. 4. understand simple algebraic equations of demand and supply and their solutions. 5. understand the meaning of various forms of price control and why governments intervene to regulate prices. 6 . be aware of other methods of determining prices, including Socialist Pricing.

The Theory of Production At the end of the second year, the student will: 1 . understand the meaning of production and productivity and the factors affecting productivity in Agriculture and Industry.. 2. appreciate the relevance of various time periods in production and the operation of the Law of Diminishing Returns. 3. understand the concepts of Returns to an Input, Returns to Scale and the factors determining the size of the firm. 4. recognise the difference between Location and Localisation of Industries and their advantages and disadvantages. 5. appreciate the difference between Specialisation and Division of Labour and their advantages and disadvantages 6. understand the concepts of Labour and Capital Intensive Methods of Production and how a choice is made between them.

Prices of Factors of Production General Objectives: The students will: 1. appreciate the factors that determine the demand for a factor of production. 2. appreciate the factors that determine the supply of a factor of production.

The Theory of Costs and Revenue General objectives: The student will: 1. understand various cost and revenue concepts and their relationships 2. recognise the characteristics of the various market structures. 3. appreciate the objectives of firms and understand how firms attain equilibrium in various market structures. 4. understand the concept of price discrimination and the conditions under which it is possible and profitable.

Distributive Trade General objectives: The student will: 1. recognise the various methods of distribution and their problems. 2. appreciate the need for agencies of distribution. 3. understand the functions of wholesalers and retailers in distribution. 4. appreciate the problems in the distributive trade and understand their remedies.

The Theory of Consumer Behaviour General objectives: The student will: 1. appreciate the various utility concepts and their relationships. 2. understand the concept of consumer equilibrium. 3. appreciate the relationship between marginal utility and the demand curve. 4 . understand the use of indifference curves in explaining the Income and Substitution Effects of a change in price. 5. understand why normally, price varies inversely with the quantity of a commodity demanded by an individual consumer.

The National Income Accounting and Determination General objectives: The students will: 1. understand the circular flow of the National Income and the various methods of measurement 2. appreciate the uses of National Income data and their limitations. 3. understand the meaning and components of aggregate expenditure. 4. understand the concept of equilibrium national income 5. understand the calculation of the multiplier. 6 . be aware of the distinction between Economic Growth and Economic Development.

Agriculture and Industry General objectives: The student will: 1. appreciate the role of agriculture in the economy of Ghana, and its problems and remedies. 2. understand the importance, difficulties and strategies of industrialisation in Ghana.

Money and Financial Institutions At the end of the third year, the student will: 1. understand what money is and its functions in an economy 2. understand the factors that determine the internal value of money 3. recognise various financial institutions and their contributions to economic development in West African countries.

Public Finance General objectives: The student will: 1 . be aware of the socio-economic activities of the government. 2. understand the structure or components of government expenditure. 3. recognise the sources of revenue for government. 4. appreciate the effect of the budget and the management of the national debt on economic development.

International Trade General objectives: The student will: 1. recognise the need for countries to trade among themselves 2. understand some terms used in international trade 3. understand the problems faced by LDCs in international trade and their solutions. 4. appreciate changes in the composition and direction of the external trade of West African countries. 5. understand exchange rates and their determination.

Economic Co-operation General objectives: The student will: 1. appreciate different forms of economic co-operation 2. understand the importance of economic co-operation as an instrument for achieving growth and development 3. appreciate the problems of economic co- 


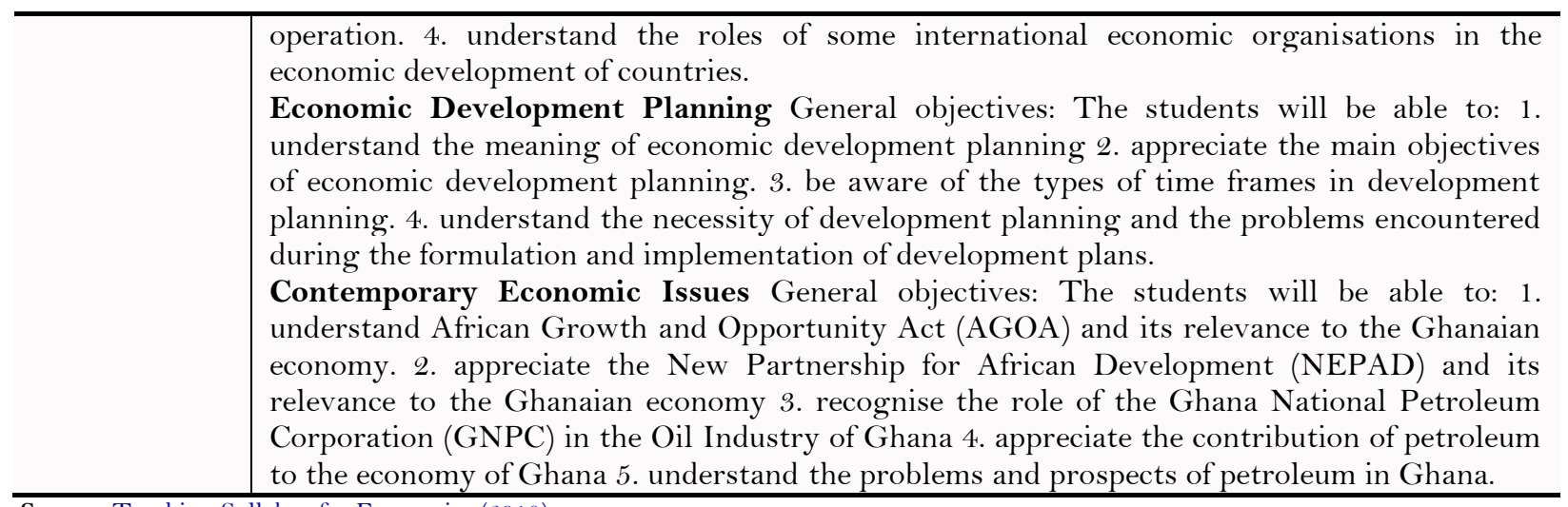

Source: Teaching Syllabus for Economics (2010)

Table-2. Distribution of SHS Economics Learning Competencies from Form 1 to Form 3.

\begin{tabular}{l|c|c|c|c}
\hline & \multicolumn{4}{|c}{ Profile Dimensions } \\
\hline Forms & Understand & Appreciate & Recognise & Be aware \\
\hline SHS 1 & 11 & 4 & 2 & 4 \\
\hline SHS 2 & 16 & 11 & 3 & 1 \\
\hline SHS 3 & 12 & 7 & 4 & 2 \\
\hline
\end{tabular}

Gaining an understanding of the basic principles of the 'management of scarce resources, the meaning of economics provides the necessary skills for understanding the types of factors of production. Additionally, the previous skills also reinforce student understanding of economic systems (economies) and subsequently the price theories of demand and supply. Form 1 students are expected to demonstrate an understanding of 'fundamental concepts in economics'; 'factors of production'; 'economic systems'; and 'price theory' (demand and supply) through hands-on activities, discussions, and teacher-guide activities. Students develop an understanding of the content through the instructional activities, which serves as a precursor for Form 2 work.

Students in Form 2 are expected to adopt a more robust approach to analyse complex economic phenomena. Students here are required to demonstrate an understanding of 'the theory of production', 'prices of factors of production', 'the theory of costs and revenue', 'the theory of consumer behaviour', 'the national income accounting and determination', and 'agriculture and industry. The syllabus suggests several teaching strategies for teachers, some of which include explanations, leading of students to appreciate concepts, providing their data, for instance on MP, TP and AP at various levels of employment of a variable input, use of discussion the data with students and leading them to suggest definitions of the concepts. Some of the strategies help students to develop and assimilate higher-order concepts and analytical abilities (Shahrokh, 1998) that they require to study different scales of production in the succeeding units. The key learning competencies reinforce subsequent contents. Students in Form 3 are expected to demonstrate an understanding of 'money and financial institutions', 'public finance', 'international trade', 'economic co-operation', 'economic development planning', and 'contemporary economic issues'. Clearly, there is no vertical linkage between the previous year's content and the succeeding year's topics. The essential content topics areas are expected to be introduced in Form 1 to further form Form 3. The student is supposed to be exposed to various tasks. Table 3 portrays the sequencing of the content in all fifteen topics in the three-year SHS economics programme. The figure sheds light on the introduction and reinforcement of those topics as students' progress through the academic years. Teachers introduce topics depending on what the students have already acquired, such as the introductory concepts (scarcity, choice, scale of preference, and opportunity cost) in SHS 1 since they lead students to define economics. In Form 1, the concept of price is introduced, and this concept is reinforced indirectly with price discrimination in Form 2. After reinforcements of the concept of price, this paves the way for introducing conditions under which price discrimination thrives. A reinforcement of the concept deepens mastery of skills. The introduction of a topic is done when the teacher presents concepts for the first time. Preferably, topics that are introduced in Form 1 must be reinforced when it is re-introduced in a different manner. It needs to have more practise drills to help students deepen their understanding of novel concepts and correct their notional errors and delusions about earlier concepts. A mastery of the content is a demonstration of students' firm understanding of the concepts. As one can see, all other things being equal, students master the concepts of demand and supply since they are reinforced as they move from one level to the other.

\section{Interview Results on Research Question 1}

A majority of the teacher-informants, six (6) of them, intimated that they do not see a vertical articulation in the content of the syllabus because just a few of the concepts are progressively sequenced in the syllabus. For example, one of the teachers in the metropolis had this to say, "The topics that need to be treated are too many to be covered in the entire school year." [Int3]. Another one [Int1] stated, "Many of the contents are taught once and never retaught; [Int7] also stated, "There is [not] many areas we can describe as vertically articulated". The majority believed that the structure of the topics makes it difficult for students to build on previous topics progressively. This they said impacted negatively on students' ability to grasp concepts and making it possible to prepare them for higher learning of economics. one [Int8] stated, "I don't think the structure of the contents make students master concepts' rather I think many concepts and competencies are not mastered as students' progress to higher levels". The intention of the spiral curriculum to allow the students to learn economics by building on their initial skills at lower levels was nonexistent. Given this, many of the teachers stated that the situation perhaps was responsible for the low enrolments in economics at the higher level. One said, "At the higher level, not many students want to do economics because they [students] may not have been adequately prepared for higher-level economics" [Int2]. Another [Int4] also stated that, “... but I believe many are afraid to do higher-level economics due to fear resulting from inadequate preparation” clearly, the 
submissions suggest that the content of the syllabus does not have vertical articulation that allows for the equipping of students to pursue further studies in economics.

Table-3. A Mapping of Content Topics in the SHS Economics Syllabus.

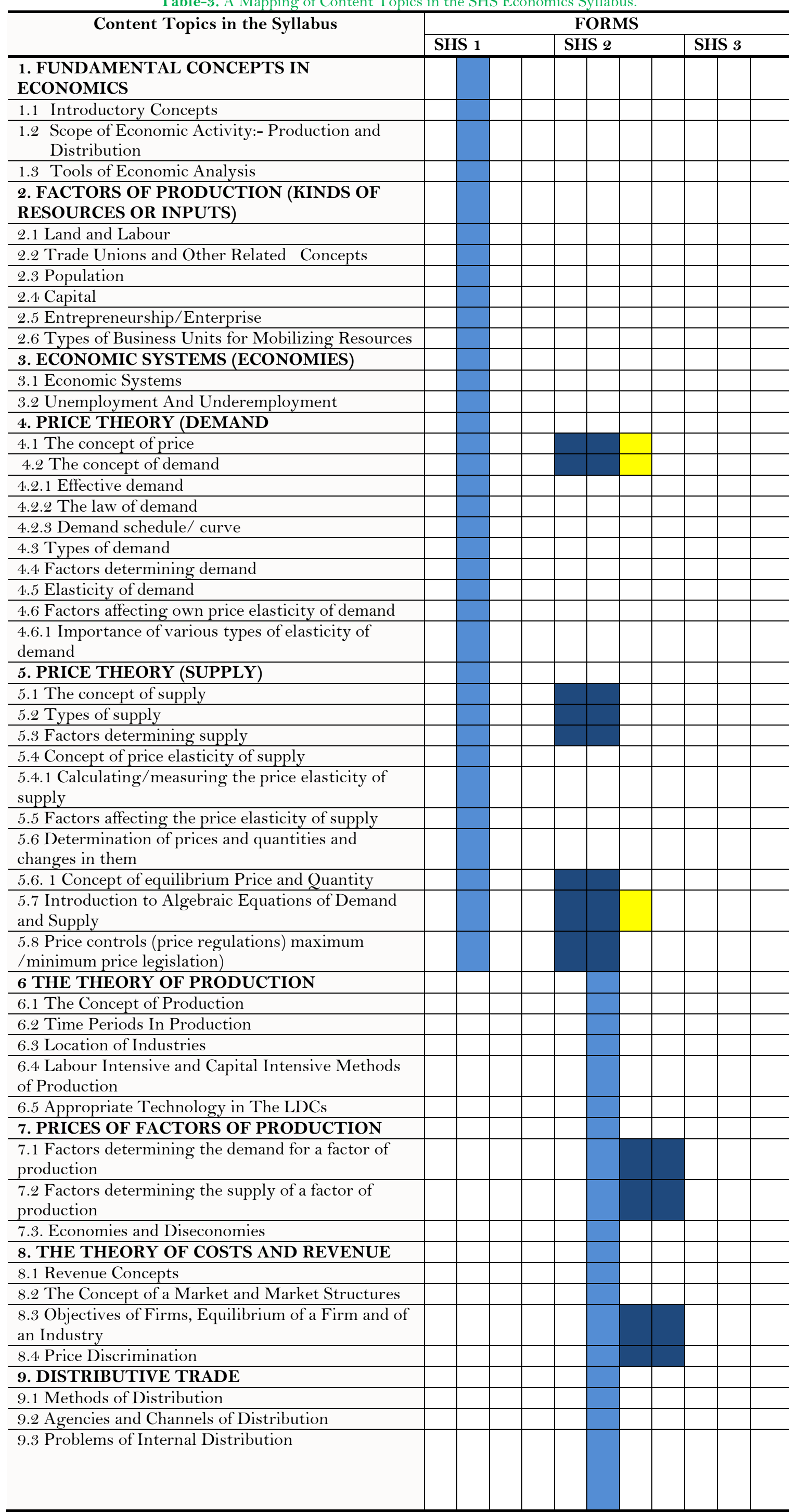




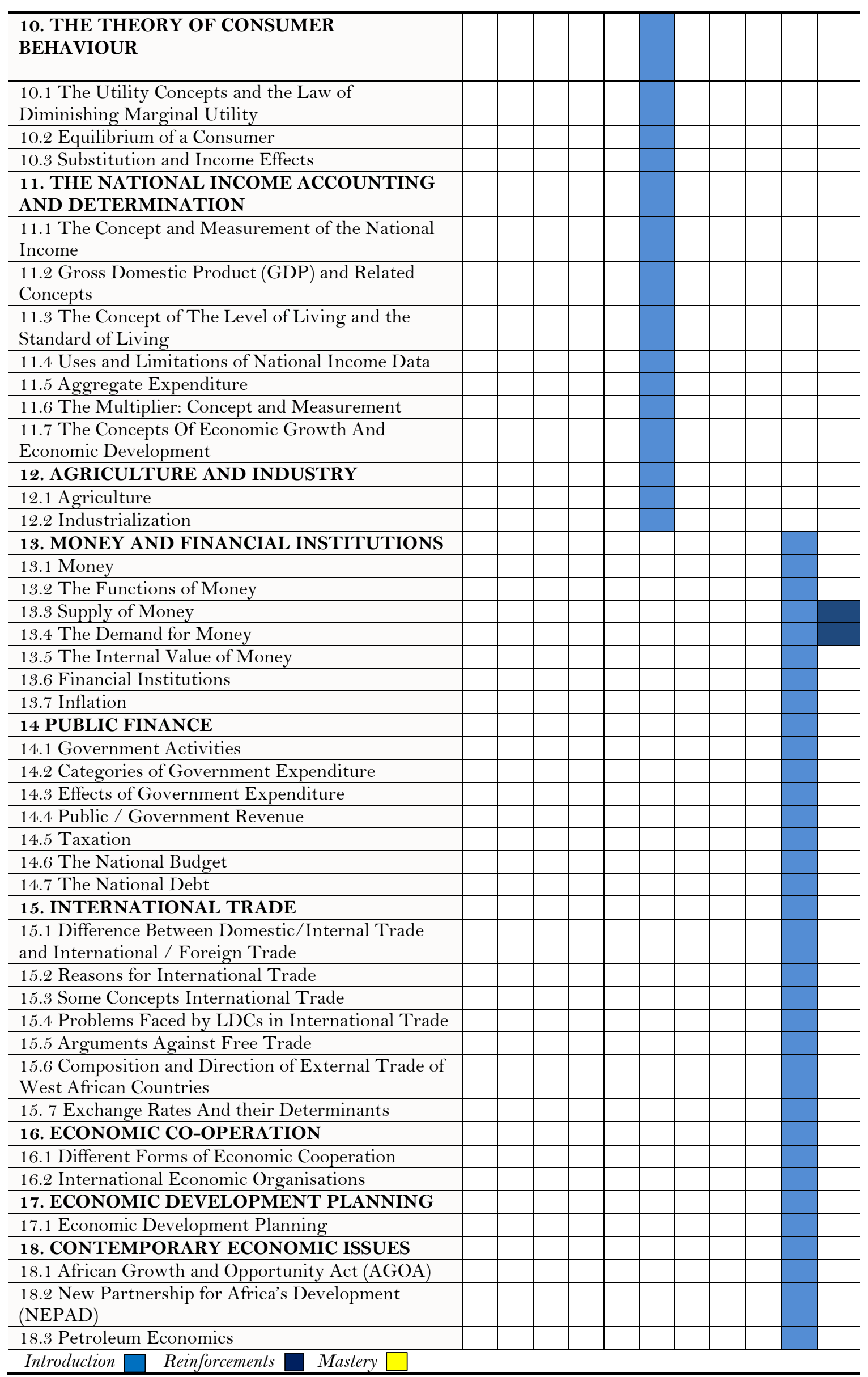

Research Question 2: Can the SHS economics curriculum be up-to-date and relevant in tackling the numerous evolving economic challenges confronting Ghana?

Through interviews of eight teachers, we obtained data to answer this research question. Asked whether they see the syllabus to be current and relevant, many of the teachers intimated that its content is relevant though it needs to be reviewed to incorporate many merging economic issues. Some of them said, "The syllabus is very relevant, but there still remain more reviews to include many topical economic issues" [Int5]. Others said, "The current syllabus has content devoted to 'contemporary economic issues, and that is fine but a lot more content need to be included" [ [Int3]; "More should be included; you know that issues like Covid-19 and it impact on the economy need a mention though I know that students learn about shocks [demand/supply] in the third year" [Int3]. Many were of the view that given the many economic issues that have emerged, the existing curriculum should be revised to reflect the changes. In sum, many of the teachers felt the current curriculum, though relevant, was not up-to-date as Paraskeva (2020) stipulated in his study. 


\section{Discussions}

Considering the student's cognitive development, topics are organised in increasing difficulty from one level of difficulty to another. That aside, some topics are reinforced as the students progress. For instance, the concept of demand allows for the learning of effective demand and the law of demand. In addition, these concepts are logically sequenced with activities that make it easier for students to understand the concept of supply. This supply concept is reinforced in Form 3 to treat the concept of supply of money and demand for money through the distinction between stock and flow where teacher helps students appreciate that money supply is a stock variable, not a flow variable. Additionally, the concept of equilibrium price and quantity is introduced in Form 1 and reinforced in Form 2 on the equilibrium of a firm and of an industry and equilibrium of a consumer. In Form 2, the concept of demand and supply, introduced in the first year, is reinforced in the treatment of demand for production factors. The two concepts are slightly different. For instance, whereas the demand for goods is direct demand, the demand for factors is derived or indirect. We directly need and purchase goods like milk, food, books, fridges, cars etc. The consumer takes into account the marginal utility of goods while purchasing the goods. However, the demand for factors is not for their own sake. They are demanded because they can be used to produce something else. Hence, the factors are demanded because of the tailor's sewing work and not the tailor himself. Hence, factors' demand is derived and their demand is affected by productivity, while the demand for goods depends upon marginal utility. But clearly, there is a reinforcement of the concepts in Forms 1 and 2 as the curriculum mapping depicts. In Form 3 , the concept of demand and supply is reinforced in the treatment of the demand for and supply of money. It appears that the two core concepts of demand and supply is so much reinforced that students get mastery of them before the end of their programme.

The topics under demand, supply, and equilibrium require a solid foundation in the lower years (Form 1) of the student and require reinforcements for deepening mastery of skills for higher-level or university economics. A majority of the teacher-informants confirmed that the reinforcement of topics facilities learning and creates the opportunity for deeper learning. This view was expressed by one of the interviewees who said, "Duplication of topics, though can waste precious time, creates avenue for deeper learning"

However, the continuity of many concepts introduced to students in Form 1 is not evident in Forms 2 and 3. For instance, students in Form (SHS) 1 are only introduced to concepts such as fundamental concepts in economics', 'factors of production, and 'economic systems' (economies). In Form 2, students are introduced to 'the theory of production', 'distributive trade', 'the theory of consumer behaviour', 'the national income, and accounting' and 'determination as illustrated in Figure 1. Discontinuing the concepts that are introduced can be seen in Form (SHS) 3 where students are introduced to the concepts of money and financial institutions (under which topics such as money and the functions of money), public finance, international trade, economic co-operation, economic development planning, and contemporary economic issues as we can glean from Figure 1.

In view of this situation, the interviewed teachers intimated that they used their own discretion in deciding the organisation of the topics in a way that satisfies the felt needs of the students. A Form 3 Teacher emphasised that "Normally, teachers do not strictly follow the arrangement of contents as we have in the syllabus [curriculum guide]. I decide which topics I treat first before others, only ensuring that all the topics are fairly treated before students write their final examinations." SHS economics teachers in all forms (1,2, and 3) should be re-oriented to emphasise certain areas of the syllabus to ensure proper progressive learning for students (Jin, Mikeska, Hokayem, \& Mavronikolas, 2019; Owusu, 2014). The teacher interviews said that training and orientations on the curriculum has been non-existent.

Clearly. The study has shown gaps between the introduction (formal) and reinforcements and/or deepening of skills of several topics in the SHS economics curriculum. Almost all the topics, with the exception of demand/supply and equilibrium analyses, are formally introduced once with no reinforcements. This situation can promote low mastery economic concepts and skills. In sum, it is obvious that the current SHS economics curriculum is not fit-for-purpose since it may be impractical for it to attain the aim of further equipping students with the basic tools for further study of economics. The present syllabus may need a careful sequencing of learning competencies according to the level of student cognitive development where topics are introduced with suitable pedagogies and instructional technologies (Kannan, 2016; Tar \& Lázár, 2019). Feedback from the interviewees suggests that the curriculum is relevant though it even though it is not up-to-date. Also, the study showed that the time allotted for teaching economics is insufficient to cover the set of learning competencies, particularly in the Form 3. Teachers therefore unintentionally create the null curriculum since some topics are skipped.

\section{Conclusion}

The is evidence that the content strands of the SHS economics syllabus are organised in increasing difficulty. However, there is a rather weak connection between and among content topics, implying little vertical articulation and coherence. The weak vertical connection in content topics creates situations where skills, knowledge and competencies are not fully mastered. Where these competencies are not mastered, the purpose of the curriculum to prepare students with the necessary tools to engage in further studies in the subject remains a mirage. The nonexistence of reinforcements in the twenty-one content topics of the syllabus adversely affects students' knowledge acquisition and ability to pursue economics at the tertiary level. Also, the current economics curriculum is relevant but needs to be kept current to confront the economic quark mire of Ghana.

\section{Recommendations}

In view of the findings, we recommend the following for consideration by the National Council for Curriculum and Assessment:

i. To keep the curriculum up-to-date and relevant, its content strands should cover the basic contemporary economic issues in Africa such the Covid-19 and its adverse effects on African economies, climate change issues, production and consumption externalities, the impact of corruption on the livelihoods of Ghanaians among many others. These new contents should be structured in such a way that they are introduced, reinforced, and reiterated (vertical articulation) to ensure student mastery. 
ii. To keep the curriculum vertically articulated and relevant to Ghana, agriculture and industrialisation, which students study only in the third year, should start from the first year to the final year so that the content can be well reinforced.

iii. To keep it up-to-date and relevant, the curriculum should be reviewed to include more content on the production of the main exportable commodities of Ghana. This will prepare students to go into the production of these essential commodities after studies.

iv. To keep the curriculum up-to-date and relevant in solving the high unemployment levels in Ghana, the syllabus should incorporate extensive content on entrepreneurship and businesses from the first to the final year.

v. Lastly, to keep the curriculum up-to-date with the latest discovery of oil in commercial quantities, the curriculum should incorporate oil and gas production in it. It should contain content on oil and gas economics from the first to the final year.

\section{References}

Allocation of Scarce Resources. (2013). Encyclopedia of corporate social responsibility, 81-81. Retrieved from: https://doi.org/10.1007/9783-642-28036-8_100049.

Bowen, G. A. (2009). Document analysis as a qualitative research method. Qualitative Research Journal, 9(2), 27 - 40. Available at: https://doi.org/10.3316/QRJ0902027.

Brooks, N. J. (2010). Spiral Curriculum. encyclopedia of curriculum studies. Available at: https://doi.org/10.4135/9781412958 806.n427.

Conducting Research Interviews. (2015). Conducting research interviews for business and management students, 37-56. Retrieved from: https://doi.org/10.4135/9781529716726.n4.

Curriculum Mapping. (2018). The SAGE encyclopedia of educational research, measurement, and evaluation. Retrieved from: https://www.doi.org/10.4135/9781506326139.n174.

De-Juanas Oliva, Á., Martín del Pozo, R., \& Pesquero Franco, E. (2016). Teaching competences necessary for developing key competences of primary education students in Spain: Teacher assessments. Teacher Development, 20(1), 123-145. Available at: https://www.doi.org/10.1080/13664530.2015.1101390.

Gibbs, B. C. (2014). Reconfiguring bruner: Compressing the spiral curriculum. Sage Journals, 95(7), 41-44. Available at: https://doi.org/10.1177/003172171409500710.

Herrick, R., Jacob, J. M., \& Richardson, J. (2003). Retention through a coordinated spiral curriculum. Paper presented at the Annual Conference Proceedings.

Jin, H., Mikeska, J., Hokayem, H., \& Mavronikolas, E. (2019). Toward coherence in the curriculum, instruction, and assessment: A review of learning progression literature. Science Education, 103, 1206-1234. Available at: https://doi.org/10.1002/sce.21525.

Kannan, P. (2016). Vertical articulation of cut scores across the grades: Current practices and methodological implications in the light of the next generation of K-12 assessments. ETS Research Report Series, 2, 1-20. Available at: https://doi.org/10.1002/ets2.12115.

Key Competence Standards of Local College Students. (2020). 2020 international conference on social and human sciences (ICSHS2020). Retrieved from: https://www.doi.org/10.38007/proceedings.0000124.

Kilic, F. (2014). Content arrangement strategies used by the academic staff. International Journal of Academic Research, 6(1), 443-449. Available at: https://doi.org/10.7813/2075-4124.2014/6-1/b.59.

Kridel, C. (2010). Spiral curriculum. Encyclopedia of Curriculum Studies, $1, \quad 809-809 . \quad$ Available at: https://www.doi.org/10.4135/9781412958806.n427.

Li, Z., \& Harfitt, G. J. (2016). An examination of language teachers' enactment of curriculum materials in the context of a centralised curriculum. Pedagogy, Culture E Society, 25(3), 403-416. Available at: https://doi.org/10.1080/14681366.2016.1270987.

Marangos, J., Fourmouzi, V., \& Koukouritakis, M. (2013). Factors that determine the decline in university student enrolments in economics in australia: An empirical investigation. Economic Record, 89(285), 255 -270. Available at: https://doi.org/10.1111/1475-493212038.

Masters, K., \& Gibbs, T. (2007). The spiral curriculum: Implications for online learning. BMC Medical Education, 7(1), 1-10. Available at: https://doi.org/10.1186/1472-6920-7-52.

Morales, M. P. E. (2017). Transition and transformations in Philippine physics education curriculum: A case research. Issues in Educational Research, 27(3), 469-492.

Owusu, A. A. (2014). Impact of teachers' acquaintance on fidelity implementation: Views of senior high school French teachers in Ghana. Journal of Education and Literature, Research Academy of Social Sciences, 1(4), 116-127.

Paraskeva, J. M. (2020). What happens with critical curriculum theory? Curriculum and the generation of utopia (1st ed., pp. 60): Routledge. Shahrokh, R. (1998). Development of higher-order thinking skills in students. Inquiry: Critical Thinking Across the Disciplines, $18(2)$, 52-64.

Spash, C. L. (2002). Science, economics and policy. Greenhouse Economics (1st ed., pp. 32): Routledge.

Tar, I., \& Lázár, T. (2019). 7Teaching intercultural competencies at the University of Debrecen. Professional Competencies in Language Learning and Teaching, 77-88.

Teaching Syllabus for Economics. (2010). Accra: Ministry of education. Retrieved from: https://mingycomputersgh.files.wordpress.com/2015/03/econs-preamble-edited-2-v-final.pdf. 